\title{
4 \\ O ENSINO DE GRANDEZAS E MEDIDAS: UMA INVESTIGAÇÃO COM UM GRUPO DE PROFESSORAS DO CICLO DE ALFABETIZAÇÃO*
}

\author{
Marcela Aparecida Duarte Oliveira Nascimento \\ Sandra Gonçalves Vilas Bôas
}

Este capítulo é fruto de nossa pesquisa de mestrado realizado junto ao Programa de Mestrado Profissional em Educação: Formação Docente para a Educação Básica. Aconteceu junto a professoras docentes dos anos iniciais do Ensino Fundamental (primeiro ao terceiro anos), em uma escola da Rede Municipal de Uberlândia-MG.). Foi dividida em quatro etapas, quais sejam: Estudo bibliográfico; Coleta de dados; Elaboração das Sequências Didáticas que compõem o Produto Educacional; Análise dos dados.

Elegemos como pergunta de pesquisa: "Quais as práticas que as professoras do Ciclo de Alfabetização da Escola X da Rede Municipal de Ensino, na cidade de Uberlândia, apresentam com relação à Unidade Temática Grandezas e Medidas"? Para responder a nossa pergunta, realizamos uma investigação de cunho qualitativo e interpretativo.

\section{Aportes teóricos: $O$ ensino de Matemática, Unidade Temática Grandezas e Medidas, Literatura Infantil e Sequência didática}

Os primeiros anos do Ensino Fundamental, é responsável pela introdução das primeiras noções, não só da Matemática, mas das diversas áreas do conhecimento e representa a base para futuros conhecimentos que as crianças terão que aprender. $O$ processo de alfabetização escolar na esfera matemática, segundo Souza (2010, p. 2) é “[...] a ação inicial de ler e escrever Matemática, ou seja, de compreender e interpretar seus conteúdos básicos, bem como saber expressar-se por meio de sua linguagem específica".

A Matemática está presente em diferentes ações cotidianas e é essencial para a vida. Deve ser ensinada não como uma disciplina estanque, mas, sim, inserida em um contexto, em que os alunos tenham a oportunidade de formular hipóteses, compartilhar suas ideias e compreendê-las de forma significativa. Assim, o ensino da matemática deve ser carregado de significados e de sentidos, deve basear-se em um trabalho de comunicação, de contextualização, de leitura,

*DOI - 10.29388/978-65-86678-49-9-0-f.71-86 
de escrita e, acima de tudo, de envolvimento do aluno na construção do conhecimento.

A Unidade Temática Grandezas e Medidas é considerada como um conhecimento básico em Matemática e, para o desenvolvimento de atividades em outras disciplinas, tais como, Geografia e História e também considerado um conhecimento elementar e de domínio dos universitários. Esse conhecimento científico assim constituído é muito importante porque, em sala de aula, o professor, especialmente dos anos iniciais, necessita de transformar esse conhecimento para uma linguagem que seja adequada às crianças, para que não lhes cause estranheza.

Segundo Muniz, Batista e Silva (2008, p. 94), o ser humano vai construindo sua noção de medidas muito antes de chegar à escola e isso nem sempre é considerado pelo professor. Nesse sentido, os autores sugerem ser importante, no processo de aprendizagem e ensino de Grandezas e Medidas, buscar essas noções dos alunos em seu contexto social, pois é com base nas suas experiências e vivências que se deve propor o ponto de partida para a ampliação de conhecimento sobre esse assunto, e não a partir de conceitos científicos já estabelecidos. Ainda segundo esses autores, a construção dos instrumentos de medidas deve estar baseada nas situações de simulação de medidas, do ato de medir, de forma a levar o aluno e a turma a escolherem as unidades de medida que julgam apropriadas (MUNIZ; BATISTA; SILVA, 2008).

Assim, nesse período de escolarização ( $1^{\circ}$ ao $3^{\circ}$ ano), é importante que as crianças tenham a possibilidade de efetuar medições de forma intuitiva, de utilizar estratégias pessoais de medida utilizando unidades não padronizadas. Nesse sentido, a ênfase está na compreensão do procedimento de medir e na exploração de estratégias pessoais.

A partir da leitura dos documentos oficiais do Ministério da Educação MEC (BRASIL, 1997, 2012, 2017), percebemos que existe neles a orientação de que o ensino de Grandezas e Medidas seja trabalhado em contextos significativos para os alunos, incluindo situações cotidianas, além de levá-los a comparar o tamanho dos objetos de forma direta (sem o uso de unidades de medidas convencionais), identificando: maior, menor, igual, mais alto, mais baixo, mais comprido, mais curto, mais grosso, mais fino, mais largo etc. $\mathrm{E}$ ainda vemos grande concordância quanto à metodologia para o ensino desse conteúdo, quando indica que o professor trabalhe com fatos reais que possibilitem aos alunos estimarem, compararem e medirem, utilizando a realidade em seu entorno (medir a altura, medir carteira, régua, lápis etc.) ao estudar o conteúdo Grandezas e Medidas no Ciclo de Alfabetização.

A Literatura Infantil aparece como um possível caminho para a apresentação das noções matemáticas presentes no cotidiano da criança de uma 
forma contextualizada e, principalmente, diferente. Smole, Cândido e Stancanelli (1999), estabelecem que a conexão entre literatura e Matemática pode implicar, entre outras coisas, em relacionar ideias matemáticas à realidade, de forma a deixar clara e explícita sua participação, sua presença e sua utilização nos vários campos da atuação humana, valorizando o uso social e cultural da Matemática.

Machado (2011) afirma haver uma complementaridade entre língua materna e Matemática. A conexão entre Matemática e Literatura é capaz de permitir diferentes situações de ensino que podem ser exploradas, pois é por meio da compreensão da leitura que o leitor se torna capaz de apropriar-se de elementos da realidade e entendê-la, como afirma Solé (1998). Desenvolver uma prática educativa a partir da literatura e dos conteúdos matemáticos contribui para que as relações entre as disciplinas sejam percebidas (SILVA, 2013).

A conexão entre esses dois conteúdos (Literatura e Matemática) é uma alternativa metodológica repleta de possibilidades, pois contribui para a formação de alunos leitores que se apropriem da leitura como prática social, capazes de utilizar os elementos necessários para compreender um texto, além de contribuir para a formação de alunos conhecedores da linguagem, de conceitos e de ideias matemáticas; que sabem utilizar diferentes estratégias para resolver problemas, seja na elaboração seja nos testes das hipóteses, além de relacionar suas experiências ao saber matemático. Assim, a Literatura Infantil pode ser uma alternativa metodológica para que os alunos compreendam a linguagem matemática neles contidas, de maneira significativa, possibilitando o desenvolvimento das habilidades de leitura de textos literários diversos e de textos com linguagem matemática específica (SILVA; RÊGO, 2006, p. 208-209).

As Sequências Didáticas (SD) constituem “[...] um conjunto de atividades ordenadas, estruturadas e articuladas para a realização de certos objetivos educacionais, que têm um princípio e um fim conhecidos tanto pelos professores como pelos alunos" segundo a definição de Zabala (1998, p. 18). Para o autor, as SD são uma forma de encadear e de articular diferentes atividades ao longo de uma unidade didática. Elas indicam a função que tem cada uma das atividades na construção do conhecimento. Tem-se, assim, um trabalho pedagógico organizado de forma sequencial, estruturado pelos professores com vistas à aprendizagem do aluno para um conteúdo específico dividido em etapas, para tornar mais eficiente o processo.

Em direção semelhante, Dolz, Noverraz e Schneuwly (2004, p. 82) afirmam que uma Sequência Didática é um conjunto de atividades escolares organizadas, de maneira sistemática, em torno de um gênero oral ou escrito. Eles afirmam, ainda, que as SD são instrumentos que podem guiar professores, propiciar intervenções sociais, ações recíprocas dos membros do grupo e 
intervenções formalizadas nas instituições escolares, tão necessárias à organização da aprendizagem em geral e ao progresso de apropriação de gêneros, em particular.

Ainda segundo os autores, as atividades propostas na sequência didática podem ser apresentadas em uma sequência que valorize a ordem e as relações que se estabelecem entre os conteúdos matemáticos e, ainda, explore as vivências dos alunos.

\section{Metodologia da pesquisa: o estudo bibliográfico e a produção dos dados}

O estudo bibliográfico foi realizado nos documentos que regem o currículo de Matemática, em teses e dissertações que pesquisam sobre a unidade temática Grandezas e Medidas, livros que apresentam referenciais teóricos sobre grandezas e medidas, sequência didática e Literatura Infantil.

A coleta de dados foi feita por meio de questionário com roteiro préestabelecido e organizado considerando os seguintes subtemas: Perfil dos docentes, suas metodologias, suas práticas pedagógicas. A partir do estabelecimento desses subtemas, foram elaboradas as questões. O objetivo do questionário foi verificar os saberes e metodologias que as dezessete professoras que atuam no Ciclo de Alfabetização da escola X apresentam com relação à unidade temática Grandezas e Medidas. Entregamos o roteiro do questionário aos dezessete professores, no entanto, apesar de nossos esforços e após diversos contatos pessoais e por telefone, obtivemos apenas quinze respostas. Assim, tornamse sujeitos desta pesquisa esses quinze professores.

Nesse sentido, após a análise dos dados do questionário, procuramos quatro professoras para entrevistá-las. $\mathrm{O}$ objetivo foi dialogar com aquelas que nos sinalizaram que utilizam livros de Literatura Infantil como recurso didático (questão $10^{1}$ ); utilizam histórias literárias para retratar as medidas em seu contexto (questão $11^{2}$ ) e ainda utilizam os livros literários do Programa Nacional do Livro Didático - PNLD/PNAIC ${ }^{3}$.

\footnotetext{
${ }^{1}$ Quais os recursos didáticos que você utiliza para trabalhar a unidade temática Grandezas e Medidas?

${ }^{2}$ De que forma você contextualiza as aulas/atividades da Unidade Temática Grandezas e Medidas?

${ }^{3}$ O PNLD PNAIC foi desenvolvido por meio de ação em parceria entre o FNDE e a Secretaria de Educação Básica por meio de Edital público de convocação de detentores de direitos autorais no país com vistas à inscrição de obras literárias que possam efetivamente contribuir com os processos de alfabetização e letramento no âmbito do PNAIC (Pacto Nacional pela Alfabetização na Idade Certa).
} 
Procedemos à realização de entrevistas semiestruturadas. Para tal, foi elaborado um roteiro com questões abertas aplicadas somente às professoras que nos indicaram fazer o uso do livro literário em suas aulas, o que nos permitiu identificar de uma melhor forma pela qual elas integram a Literatura Infantil com os objetos de conhecimento da unidade temática Grandezas e Medidas.

\section{O questionário e a entrevista: análise e discussão dos resultados}

Para a melhor compreensão dos resultados, elegemos duas categorias, quais sejam: constituição dos saberes na formação inicial e continuada, práticas de sala de aula no que concerne ao planejamento, à metodologia e aos instrumentos utilizados para o ensino de aprendizagem dos conceitos de grandeza e de medida e relativos à utilização da literatura como um subsídio para o ensino de Matemática especificamente à Unidade temática Grandezas e Medidas

Todas as professoras nos afirmaram considerar importante o estudo de Grandezas e Medidas no Ciclo de Alfabetização. Assim, foi importante conhecer e compreender qual o grau de facilidade e/ou dificuldade das professoras ao realizar o trabalho com Grandezas e Medidas. Nesse sentido, elas foram orientadas a responder o questionário segundo uma escala, qual seja, "Numere as unidades temáticas de 1 a 4, segundo seu grau de facilidade. Sendo 1 para aquele que você possui mais dificuldade e 4 para aquele que você tem mais facilidade". Entre as quinze professoras entrevistadas, somente uma nos informou ter facilidade no trabalho com a Unidade Temática Grandezas e Medidas. As demais nos informaram suas dificuldades em diferentes escalas, quais sejam: cinco disseram ter essa dificuldade em um nível 3, quatro em um nível 2 e cinco em um nível 1. Esse resultado muito nos preocupou, em função da importância dessa Unidade Temática. Números e operações foram a Unidade temática com maior índice de facilidade, também por ser a mais trabalhada.

Esses resultados nos sinalizam a necessidade que as professoras têm de investir em sua formação contínua, seja em estudos, assim como, como na busca de recursos pedagógicos que as auxiliem em suas aulas.

Consideramos importante investigar a importância atribuída por elas em comparação com os demais objetos de conhecimento. Nesse sentido perguntamos às professoras: - Qual objeto de conhecimento você acredita ser mais importante para ser trabalhado no Ciclo de Alfabetização?

Seis professoras nos afirmaram que consideram todos objetos de conhecimento (Medida de comprimento, Medida de capacidade, Medida de massa, Medida de tempo e Sistema monetário brasileiro) importantes, não 
havendo grau de diferenciação. Cinco professoras consideram ser mais importante trabalhar as Medidas de tempo. Três professoras acreditam ser importante trabalhar com maior ênfase o Sistema Monetário Brasileiro. Apenas uma professora a Medida de comprimento como a mais importante a ser apresentada para as crianças. Por fim, vale destacar que a alternativa medidas de massa e capacidade não foi considerada em sua magnitude, exceto pelas seis professoras que consideram todas as medidas igualmente importantes.

Ainda na infância, no seu cotidiano, mesmo antes de frequentarem a escola, as crianças participam de atividades que utilizam expressões nas quais podemos perceber a presença de noções relacionadas a Grandezas e Medidas. Desse modo, os documentos Brasil (1997, 2012, 2017) e Uberlândia (2011) evidenciam o papel importante no currículo, do estudo de Grandezas e Medidas, e destacam que ele mostra claramente ao aluno a utilidade do conhecimento matemático no cotidiano. Nesse sentido buscamos investigar junto às professoras a frequência da utilização dos documentos oficiais na elaboração do planejamento anual de Matemática, se os conteúdos e as orientações didáticas contidas nos documentos oficiais, no que refere às Grandezas e Medidas, encontram-se nas propostas de trabalho dos professores.

O questionário nos mostrou que esses documentos são referência para elaboração do planejamento das professoras e que elas utilizam no simultaneamente, no entanto, esse percentual é variável, qual seja: o PCN'S é utilizado por $60 \%$ das professoras, os DA - Direito de Aprendizagem é utilizado por $73 \%$ das professoras, BNCC por $60 \%$ das professoras afirmam essa prática e as Diretrizes Curriculares Municipais de Uberlândia em uma utilização de $93 \%$.

A unidade temática Grandezas e Medidas tem grande potencial para o trabalho com a Matemática aplicada, desde que bem contextualizada, possibilita às crianças que se familiarizem com o seu uso e seus significados. A Matemática que queremos verificar se as professoras realizam e na qual nos apoiamos é aquela que tem um contexto, seja ela teórica ou aplicada. Segundo Granja e Pastore (2012, p. 11) se bem contextualizado, um tema teórico, a princípio árido, pode-se tornar desafiador e instigante para o aluno, e um tema de Matemática Aplicada pode ser fascinante e encantador. Para investigar essa prática, apresentamos às professoras a pergunta: - De que forma você contextualiza as aulas/atividades da Unidade Temática Grandezas e Medidas? Foram apresentadas às professoras cinco alternativas, das quais elas poderiam assinalar quais as utilizadas por elas.

Todas as professoras nos afirmaram que contextualizam as aulas/atividades da Unidade Temática Grandezas e Medidas. Doze professoras nos afirmaram que contextualizam suas aulas por meio de exemplos do cotidiano. Onze professoras nos informaram que utilizam o livro didático. No 
que concerne à contação de histórias, oito professoras dizem fazer uso dessa metodologia. No entanto, apenas quatro nos afirmaram utilizar como recurso didático a Literatura Infantil. Diante desse resultado, detectamos certa incoerência no discurso das professoras. Seis professoras buscam na resolução de problemas uma possibilidade para contextualizar suas aulas. Aulas de campo não é uma prática no cotidiano da sala de aula, visto que apenas três nos disseram fazer uso dessa metodologia.

O trabalho com Grandezas e Medidas, que poderia ser abordado de forma aplicada, geralmente restringe-se aos exemplos clássicos, que se repetem, sem muita inspiração, nos livros didáticos, ou às situações artificiais de aplicação. Essa realidade é também refletida nas ações das professoras, uma vez que doze delas afirmam utilizar livros didáticos e realizarem atividade com instrumentos convencionais.

O Ministério da Educação, por meio do PNAIC - Pacto Nacional de Alfabetização na Idade Certa e o PNLD - Programa Nacional do Livro Didático, enviou às escolas obras literárias para todas as salas de aula do Ciclo de Alfabetização em junho de 2013. Foram 75 títulos distribuídos em três acervos. Nesse sentido, elegemos uma pergunta com o objetivo de investigar se esses livros estão sendo utilizados também nas aulas de Matemática. Dez professoras nos afirmaram que, às vezes, utilizam os livros literários do PNLD enviados à escola por meio do PNAIC. Esse dado nos sugere uma incoerência, uma vez que, ao cruzarmos as respostas do questionário, percebemos que apenas duas professoras nos afirmaram utilizar livros literários como recurso didático.

Uma das recomendações mais frequentes nas orientações curriculares atuais é que procuremos estabelecer, no ensino, ligações entre os campos da própria Matemática, qual seja estabelecido na BNCC (BRASIL, 2017) por Unidades Temáticas. Assim, achamos de fundamental importância investigar se os professores conseguem promover essa integração.

Doze professoras disseram que sim e apenas três afirmaram que não possuem essa prática. Oito professoras conseguem integrar a Unidade temática Números e operações com Grandezas e Medidas frequentemente. Doze professoras integram a Geometria a Grandezas e Medidas, mas o fazem somente às vezes. Dez professoras conseguem integrar à Probabilidade e Estatística somente às vezes.

Para compreender um pouco da prática das quinze professoras que, no questionário, responderam que utilizam livros literários para ensinar Matemática, optamos por realizar com cada uma delas, individualmente, uma entrevista. 
Para compreender as respostas da entrevista, elegemos três categorias, quais sejam: modo de utilizar os livros literários para ensinar Matemática; importância e contribuição do livro literário para as aulas de Matemática; exemplo de como se usa a literatura nas aulas de Matemática.

Sobre o modo de utilizar os livros, as professoras nos informaram que possuem a preocupação de fazer uma conexão da história com o conteúdo matemático a ser ensinado.

Relativo aos contributos e importância do livro literário na aula de Matemática, as professoras destacaram que: (a) possibilita o trabalho interdisciplinar; (b) amplia o vocabulário, (c) desperta o interesse das crianças para o conteúdo; (d) ajuda a lembrar-se dos conteúdos, pois se lembram da história; (e) assimilam melhor o conteúdo, porque os livros têm desenho, figura, cores e a história; (f) permite à criança imaginar, fantasiar, e aprender melhor e (g) ajuda na interpretação de textos e problemas. Essas observações são afirmadas por Calvim (1991, apud SMOLE, 1999), quando nos afirma que a Literatura é capaz de desenvolver na criança a capacidade de imaginar, de fantasiar e de criar a partir das imagens visíveis do texto. Referente aos exemplos, as professoras citaram os seguintes livros que já foram utilizados em suas aulas de Matemática, que são: "Quem vai ficar com o pêssego" de YOON, Ah-Hae; YANG, Hye-Won, 2011 "Dez Sacizinhos" de Tatiana Belinky, 2007 e "Sanduiche da Maricota" de Avelino Guedes, 1995.

\section{O produto educacional:}

Como produto de nossa dissertação de Mestrado (NASCIMENTO, 2018) construímos um Caderno de sequências didáticas norteadas por livros da Literatura Infantil e pela Unidade Temática Grandezas e Medidas, intitulado "Literatura Infantil sequência didática e o ensino de Grandezas e Medidas no Ciclo de Alfabetização - uma conexão possível".

Os livros literários utilizados são parte integrante do acervo enviado as escolas por meio do PNLD - Programa nacional do livro didático e do PNAIC - Pacto Nacional de Alfabetização na Idade Certa.

As sequências didáticas do caderno apresentam os objetivos de aprendizagem e as habilidades e os respectivos objetos de conhecimento da BNCC aos quais esses objetivos estão relacionados. Essas sequências didáticas objetivam discutir elementos que favoreçam a compreensão dos conceitos de medida. Para alcançar esse objetivo, as atividades têm como ponto de partida as unidades de medidas não convencionais e conduzem à percepção da necessidade de padronização das unidades de medidas, assim como a compreensão dos processos de medição e das características do instrumento escolhido. 
Os Cadernos de Sequência Didática estão assim organizados: a primeira sequência didática do caderno é norteada pelo livro Gabriel tem 99 centímetros, da autora Annette Huber (2013), que possibilita abordarmos noções de medida de comprimento, comparação e estimativa. Em seguida, abordando as noções de Medidas de Tempo, a segunda sequência é baseada no livro "Que horas são?” autoria de Guto Lins (2009) que traz atividades rotineiras, que levam a criança a se familiarizar com a passagem do tempo, preparando-a para a leitura dos ponteiros do relógio. Ambas as sequências estão estruturadas da seguinte forma: primeiro temos a apresentação da situação, em que a ideia e/ou os personagens são apresentados aos alunos, tendo eles que expor oralmente e ou por meio de registro, o que acham que está por vir. É de extrema importância esta etapa, visto que "[...] a produção inicial pode 'motivar' tanto a sequência como o aluno.” (DOLZ; NOVERRAZ; SCHNEUHWLY, 2004).

Em seguida, apresentam-se os módulos, tendo respectivamente seis e quatro módulos cada uma das sequências apresentadas. E dentro dos módulos, diferentes sugestões e atividades como: Sugestão de questionamentos, rodas de conversa, contação de história, avaliação, atividades investigativas, atividades para registro e brincadeiras.

E por fim, a sequência apresenta a Produção Final, podendo ser, se o professor assim desejar, um momento para a avaliação do tipo somativa. O importante é que o aluno encontre, de forma explícita, os elementos trabalhados em aula e que estes sejam os objetos de avaliação processual ao final de cada módulo.

Em função do limite de páginas, apresentamos somente parte de uma das Sequencias didáticas construída a partir do livro "Gabriel tem 99 centímetros" (Huber, 2013). Destacamos que esse livro é parte integrante das caixas enviadas às escolas por meio do PNAIC. Nas páginas que seguem, apresentamos as ações, bem como, o desenvolvimento das sequências didáticas.

O livro traz a mãe de Gabriel dizendo que ele já é um menino bem grande. Mas, de vez em quando, ele acha que ainda tem de crescer muito. Gabriel se compara o tempo todo com várias coisas. O livro possibilita abordar noções de medida de comprimento, comparação e estimativa.

Ação introdutória: Dois dias antes de iniciar a Sequência didática, levar para a sala de aula uma representação dos personagens Gabriel e sua mãe (por exemplo, fantoche, desenho, bonecos etc.) e colocar em um lugar de destaque na sala de aula. Certamente os alunos irão questionar. Diga que são pessoas que conhecerão dentro de dois dias. Durante esses dois dias que antecedem a leitura, vá fazendo um Marketing sobre a futura atividade (quem eles são, o que farão, o que podem trazer a nós), o objetivo dessa ação é criar um desejo nas crianças de ouvirem a história e o que está por vir na Sequência Didática. 
Módulo 1: Roda de conversa para contação da história, este momento, tem como objetivo, estabelecer uma relação lúdica com a Obra Literária e conduzir um diálogo para explorar a capa e contar a história. Escolha um lugar agradável e sente-se com as crianças. (biblioteca, pátio, jardim).

Para conduzir a primeira rodada, privilegie questões norteadoras, tais como: Qual o título? Quem é o autor? Quem é o ilustrador? Qual a função dessas pessoas? O que traz de mensagem a ilustração da capa? Sobre o que tratará a história? Para esse momento faça o uso do livro para mostrar as gravuras, chamar a atenção para algum detalhe da história, ler uma frase, um parágrafo, levantar hipóteses sobre o que virá depois.

Em seguida, qual seja, momento de contação da história e interpretação do contexto do livro, procure estimular as crianças fazendo questionamentos acerca dos próximos acontecimentos da história. Sugestão de questionamentos ${ }^{4}$ : "Eu me chamo Gabriel e, hoje de manhã, minha mãe, tirou minha medida"; O que vocês acham o que é medir? "Agora, eu tenho 99 centímetros. A mamãe me disse que é quase 1 metro; $\mathrm{O}$ que significa essa palavra metro? Dê alguns exemplos. Permita que as crianças falem livremente. Esse é um momento de escuta dos saberes que as crianças trazem a priori. Gabriel fala que "ser pequeno tem algumas vantagens", vocês lembram quais vantagens ele fala? Ele também fala que "ser grande é bom", Por que Gabriel fala que é bom ser grande? Vocês concordam com Gabriel? Poderiam me dizer outras vantagens que temos em ser pequenos e ser grandes?

A partir da leitura do livro e das respostas das crianças, chame a atenção dos alunos para as grandezas que podemos medir e que existem ao nosso redor e em nosso próprio corpo, como por exemplo, comprimento, altura, largura, "peso". Com essa ação está se preparando a criança para o próximo módulo.

Módulo 2: Medir com passos, Brincadeira Mamãe, posso ir? tem como objetivo, vivenciar medida de comprimento de forma não convencional.

Para essa brincadeira, será necessário construir 2 dados (tipo de passo e quantidade). Inicialmente, fazer o sorteio de quem será a mamãe; apresentar o dado tipo de passo e o dado de quantidade e explicar os três tipos de passos, conforme figura 1: passo de formiguinha, passo de cão, passo de elefante e permaneça com está. A segunda ação é marcar o ponto de partida. Cada um na sua vez lança os dados. Vence quem chegar à mamãe primeiro A mamãe dá a ordem de acordo com o que foi sorteado no dado.

${ }^{4}$ Os questionamentos são apresentados em linguagem informal para que se possa estabelecer um diálogo mais próxima a linguagem da criança. 
Figura 1: Passos para medir

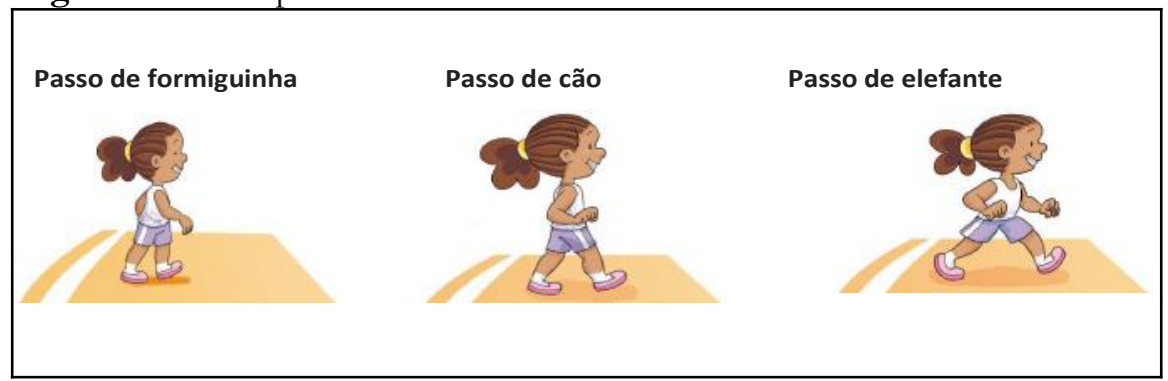

Fonte: Coleção Bem-me-Quer - Matemática $1^{\circ}$ ano, p. 156, 2017.

Após a brincadeira, é fundamental investigar as ações. Nesse sentido, organize uma roda de conversa sobre a variabilidade das medidas dos passos. Sugestão de questionamentos: O que é melhor para ganhar o jogo: dar passos de elefante ou passos de formiguinha? Por quê? Qual a diferença entre eles? Todos os passos de cão são do mesmo tamanho? Explique; elabore situações problemas a partir desse contexto (Ex: Carlos e Gabriel têm a mesma idade e estavam brincando de Mamãe posso ir? Carlos deu dois passos, um de formiguinha e um de cão. Gabriel deu dois passos de dois passos de cão. Quem está à frente?).

É chegado o momento da realizar a atividade 3, que tem como objetivo, apresentar para os alunos trechos do livro (figura 2) e fazer uma reflexão. Sugestão de questionamentos: Por que a mãe de Gabriel dá menos passos que ele para percorrer uma certa distância? Por que Gabriel fica mais cansado que a mãe? Subir escada para você é cansativo como é para Gabriel?

Figura 2: cenas do livro

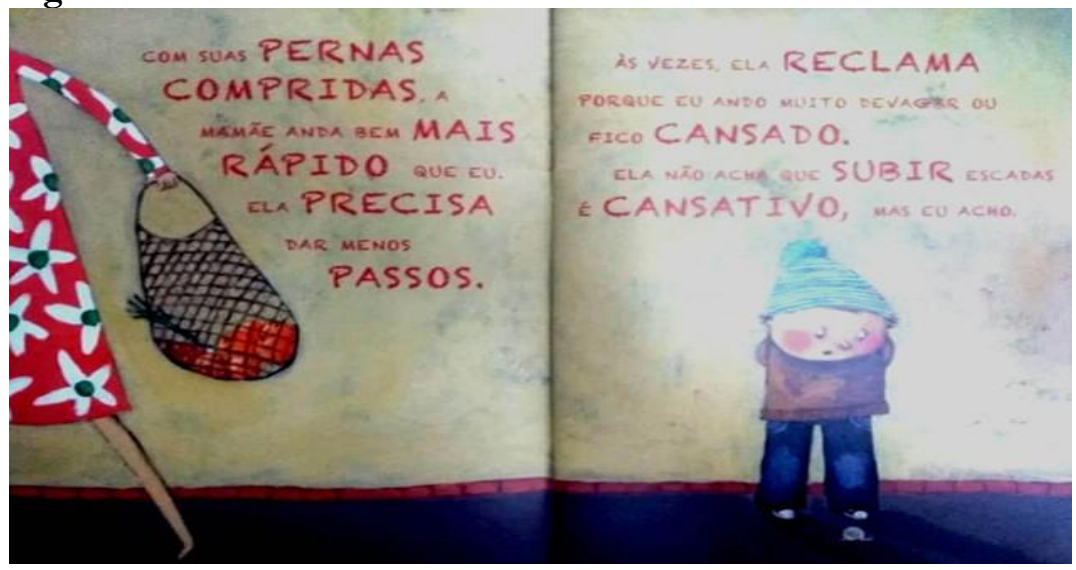

Fonte: Huber, 2013, p. 10-11 
No Módulo 3, o objetivo é realizar medições utilizando unidades de medidas não padronizadas. Para motivar as crianças a realizar a atividade comparando-se com a medida de Gabriel, trazer a história no contexto da sala de aula, mostre a imagem (figura 3) para as crianças. Sugestões de questionamentos: Gabriel, o menino do livro tinha 99 centímetros... E, pensando nisso, agora me bateu uma curiosidade de saber quem é o maior e o menor aluno da turma; olhando todos os que estão na sala, quem será o maior? Quem é o menor? E como é possível comprovar que isso é verdade? Como podemos medir? Mas!! Na sala não temos fita métrica, o que poderemos usar para medir? (sugerir o barbante).

Figura 3: trecho o livro

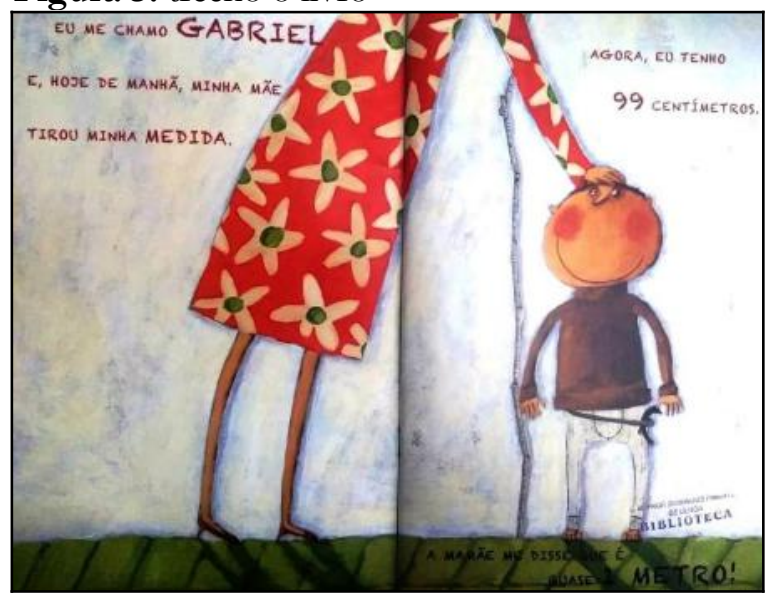

Fonte: Huber, 2013, p. 2-3

Após o diálogo inicial, é momento de propor aos alunos o desafio, qual o seu tamanho. Para tal, sugerimos as seguintes ações: Dispor em papel kraft, um painel com nome e foto de cada aluno; realizar a medição de todos os alunos com barbante, anexando no painel o nome e a "altura" de cada um; discutir com os alunos o painel de medidas, levantando questões que enfoque estimativa comparação e quantidade (Quem é o maior, menor, mesmo tamanho). Elabore em conjunto com as crianças situações problema envolvendo as medidas.

O Módulo 4 - Instrumento convencional (fita métrica), o objetivo é reconhecer unidades padronizadas de medida: metro e centímetro; conhecer e perceber a utilidade das Medidas padronizadas. A Abordagem inicial é conhecer uma fita métrica. Realize as seguintes ações: Apresentar a fita métrica: Hoje trouxe uma fita métrica, que é o instrumento mais utilizando para realizar 
medições; contar historicamente como surgiu a fita métrica; construir com as crianças uma fita métrica;

Conhecer em centímetros as alturas dos alunos da turma, comparando se são maiores ou menores que os personagens (Gabriel e sua mãe), é o objetivo dessa atividade. Para iniciar as discussões, apresentar para os alunos o trecho da história (figura 5). Sugestão de questionamentos: Gabriel, diz que a mãe dele é 76 centímetros maior que ele, será qual a altura de sua mãe? Leve para sala de aula fita métrica e solicite aos alunos que meçam uns aos outros e também a professora.

Figura 4: trecho do livro

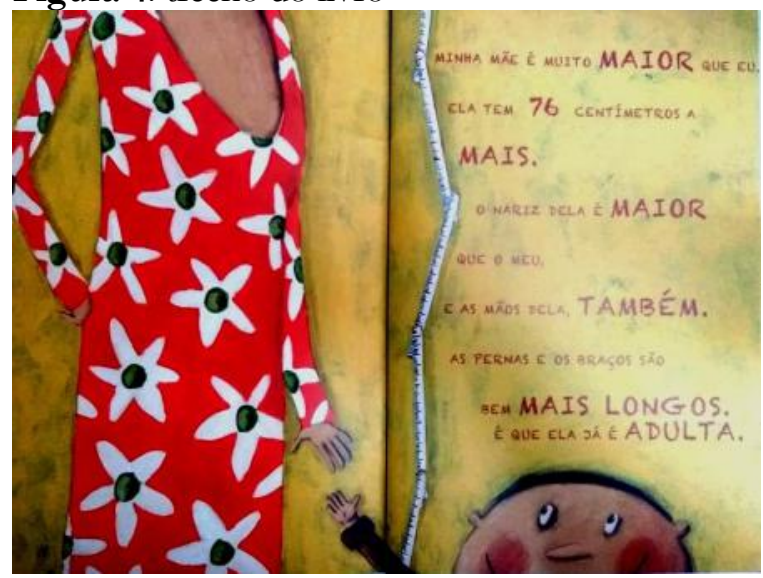

Fonte: Huber, 2013, p. 3-4

Uma vez realizada as medidas, elaborar quadro com os resultados métricos da turma, Sugestão de questionamentos: Confrontar os resultados medidos com o cordão, o resultado das medidas ficou igual? É mais fácil medir com fita métrica que com o cordão? Vocês sentiram dificuldade em usar esse tipo de sistema de medida? Por que vocês acham que as medidas foram padronizadas? Propor problematizações orais e escritas na lousa; mostrar que os instrumentos não convencionais não nos dão valores precisos.

No módulo 5, o objetivo é a Construção e leitura de tabelas e de gráficos de pictograma e colunas simples. 
Figura 5: Capa do livro

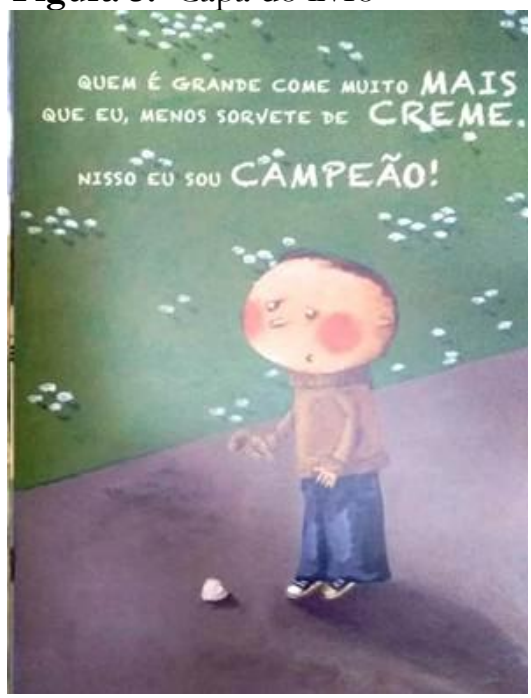

Fonte: Huber, 2013

A história no contexto da sala de aula - Roda de conversa, Sugestão de questionamentos: Por que vocês acham que quem é grande come mais? Por que Gabriel disse isso? Será verdade? Gabriel afirma que com relação ao sorvete de creme, ninguém ganha dele! E você qual seu sabor preferido? Como podemos investigar qual o sabor preferido de cada aluno?

Ação: Realizar uma pesquisa para descobrir qual sabor de sorvete preferido da turma. Entregar para cada aluno o desenho de uma casquinha e da bola de sorvete pedir para colorirem a bola de acordo com sabor de sua preferência e colar na casquinha.

Para construir o gráfico realiza-se o seguinte procedimento: Colar as casquinhas (molde no anexo) no papel que será o aporte do gráfico/ pictograma; construir a tabela e, por fim, interpretar os dados: comparar os que gostam mais e os que gostam menos de determinado sabor. Levantar questionamentos, tais como: - Será quantas crianças gostam do mesmo sorvete que Gabriel? Qual tem maior preferência?

Considerações: Ao final de cada módulo fazer atividades de registro para melhor fixação, podendo ser feitas até mesmo como atividades de para casa. Para esse momento, o importante é que o aluno encontre, de maneira explícita, os elementos trabalhados em aula e que eles sejam os objetos de avaliação processual, ao final de cada módulo. A produção final é o momento, se assim se desejar, para uma avaliação do tipo somativa. 


\section{Considerações finais}

Reiteramos que a partir das respostas, verificamos que algumas das professoras fazem uso dos livros literários como recurso para ensino de Matemática, nas diferentes unidades temáticas, inclusive Grandezas e Medidas. De nossas análises, a partir do questionário, percebemos a necessidade que os professores têm de um apoio para suas práticas pedagógicas.

De nossas leituras e resultados de nossa investigação, inferimos que os livros de Literatura Infantil podem auxiliar o trabalho didático metodológico para o ensino de alguns conteúdos de Matemática, pois, ampliam a possibilidade de integração das diferentes dimensões do conhecimento, rompem com a monotonia, despertam a curiosidade, melhoram a oralidade e a capacidade de argumentação e de estruturação do pensamento e, sem dúvida, aumentam enormemente a capacidade de interpretação das mais variadas situações sejam elas matemáticas ou não.

Destacamos que a Literatura e a Matemática podem sim formar um "par perfeito", pois a Literatura é uma possibilidade que pode proporcionar ao aluno a leitura e a compreensão dos elementos matemáticos de forma mais prazerosa e lúdica e, assim, apropriar-se desses conhecimentos de forma efetiva.

\section{Referências}

BRASIL. Ministério da Educação (MEC). Secretaria de Educação Fundamental (SEF). Parâmetros Curriculares Nacionais: introdução aos Parâmetros Curriculares Nacionais. Brasília, DF: MEC/SEF, 1997a.

BRASIL. Ministério da Educação. Base Nacional Comum Curricular - BNCC 2. versão. Brasília, DF, 2017.

BRASIL. Secretaria de Educação Básica. Diretoria de Currículos e Educação Integral - DICEI. Coordenação Geral do Ensino Fundamental - COEF.

Elementos conceituais e metodológicos para definição dos direitos de aprendizagem e desenvolvimento do Ciclo de Alfabetização (primeiro, segundo e terceiro anos) do Ensino Fundamental. Brasília: MEC, 2012.

BORDEAUX, A. L. et al. Novo bem-me-quer matemática, $1^{\circ}$ ano. $4^{a}$ ed. São Paulo: Editora do Brasil, 2017.

BRASIL. Pacto nacional pela alfabetização na idade certa: Grandezas e Medidas. Ministério da Educação Secretaria de Educação Básica, Diretoria de Apoio à Gestão Educacional MEC/SEB. Brasília, 2014.

DOLZ, J.; NOVERRAZ, M.; SCHNEUWLY, B. Sequências didáticas para o oral e a escrita: apresentação de um procedimento. In: DOLZ, J.; 
SCHNEUWLY, B. et al. Gêneros orais e escritos na escola. Trad. e org. Roxane Rojo e Glaís Sales Cordeiro. Campinas: Mercado das Letras, 2004.

GRANJA, C. E.; PASTORE, J. L.; Atividades Experimentais de Matemática nos anos finais do Ensino Fundamental. São Paulo: SM, 2012.

HUBER, A.; OLTEN, M. Gabriel tem 99 centímetros. São Paulo: Saber e Ler, 2013.

LINS, Guto. Que horas são?. São Paulo: Mercuryo Jovem, 2005.

MACHADO, Nílson José. Matemática e língua materna: análise de uma impregnação mútua. [S.l: s.n.], 2011.

MUNIZ, C.A.; BATISTA, C.O.; SILVA, E. B. Módulo IV - Matemática e Cultura: Decimais, Medidas e Sistema Monetário. Brasília: Universidade de Brasília, 2008.

NASCIMENTO, Marcela Aparecida Duarte Oliveira. O ensino de grandezas e medidas: uma investigação com um grupo de professoras do ciclo de alfabetização / Marcela Aparecida Duarte Oliveira Nascimento. - Uberlândia, $2018.124 \mathrm{f}$.

SILVA, A. C. Matemática e Literatura Infantil: um estudo sobre a formação do conceito de multiplicação. 2003. Dissertação (Mestrado em Educação) Centro de Ciências Humanas Letras e Artes, Universidade Federal da Paraíba, João Pessoa, 2003.

SILVA, A. C.; RÊGO, R. Matemática e Literatura Infantil: Um estudo sobre a formação do conceito de multiplicação. In: BRITO, M. R. F. (org.). Soluções de problemas e a Matemática escolar. Campinas: Alínea, 2006. p. 207-236.

SOUZA, Ana Paula G. de; OLIVEIRA, Rosa Maria M. A. de. Articulação entre Literatura Infantil e Matemática: intervenções docentes. BOLEMA: Boletim de Educação Matemática, Rio Claro, v. 23, p. 955-975, dez. 2010.

SMOLE, C: CÂNDIDO, P.; STANCANELLI, R. Matemática e Literatura Infantil. 4. ed. Belo Horizonte: Lê, 1999.

SOLÉ, I. Estratégias de leitura. 6. ed. Porto Alegre: ArtMed, 1998.

UBERLÂNDIA. Secretaria Municipal de Educação. Diretrizes Curriculares Municipais. Uberlândia, 2011.

ZABALA, A. A prática educativa: como ensinar. Porto Alegre: Artmed, 1998.

YOON, A. H.; YANG, H. W. Quem vai ficar com pêssego? São Paulo: Callis, 2011. 